Primljen / Received: 7.10.2012.

Ispravljen / Corrected: 22.12.2012.

Prihvaćen / Accepted: 27.12.2012.

Dostupno online / Available online: 15.1.2013.

\section{The stress and time dependent behaviour of soft rocks}

\section{Author:}

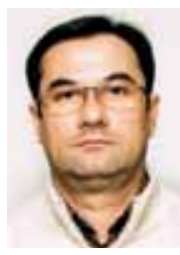

Prof. Zvonko Tomanović, PhD. CE

University of Montenegro

Faculty of Civil Engineering in Podgorica zvonko@ac.me
Original scientific paper

\section{Zvonko Tomanović}

\section{The stress and time dependent behaviour of soft rocks}

In mathematical description of time dependent behaviour of a material, the basic task is to define deformations as a function of time, stress, and temperature. The influence of stress state on deformation response of the rock mass has been experimentally determined on uniaxial, bi-axial and three-axial specimens of marl by short loading, and by creep tests in the period from 3 to 360 days. The suggested model may be applied for description of time dependent deformations under full constant load, but also after the total or partial unloading, which is significant for the stress condition in the rock mass around the tunnel opening.

Key words:

creep, soft rock, rheological model, lateral stress

Izvorni znanstveni rad

\section{Zvonko Tomanović}

\section{Ponašanje mekih stijena ovisno o naprezanjima i vremenu}

Pri matematičkom opisivanju ponašanja nekog materijala, osnovnijezadatak definiratideformacije u funkciji vremena, naprezanja i temperature. Utjecaj stanja naprezanja na deformacijski odziv stijenske mase eksperimentalno je određen jedoosnim, dvoosnim i troosnim ispitivanjima nanošenjem kratkotrajnog opterećenja, te ispitivanjem puzanja u vremenu od 3 do 360 dana. Predloženi model može se primijeniti za opisivanje vremenski ovisnih deformacija pod punim trajnim opterećenjem, ali i nakon ukupnog ili djelomičnog rasterećenja, što je važno za stanje naprezanja u stijenskoj masi oko otvora tunela.

Ključne riječi:

puzanje, meka stijena, reološki model, bočno naprezanje

Wissenschaftlicher Originalbeitrag

Zvonko Tomanović

\section{Spannungs - und zeitabhängiges Verhalten von weichem Gestein}

Die grundlegende Aufgabe bei der mathematischen Beschreibung eines Materials ist, Verformungen in Funktion von Zeit, Spannung und Temperatur zu definieren. Der Einfluss des Spannungszustandes auf das Verformungsverhalten der Gesteinsmasse ist experimentell ermittelt worden, und zwar durch Versuche an einachsigen, zweiachsigen und dreiachsigen Gesteinsproben unter Kurzzeitlasten und durch die Prüfung des Kriechverhaltens nach 3 bis 360 Tagen. Das vorgeschlagene rheologische Modell ermöglicht die genaue Beschreibung von zeitabhängigen Verformungen von Gestein unter Dauerlasten, kann aber auch für vollständig oder teilweise entladene Gesteinsmassen angewandt werden. Diese Eigenschaft ist von erheblicher Bedeutung, vor allem für die Darstellung des Spannungs- und Deformationszustandes von Gesteinen, die Tunnelöffnungen umgeben. 


\section{Introduction}

Laboratory creep tests were carried out on marl specimens In order to formulate a rheological model of soft rocks, which includes time dependant deformations. A number of specific rheological material coefficients and parameters need to be defined to enable proper formulation of a rheological model. This task is further complicated by the fact that, on the one hand, a mathematical model is required so as to encompass as many material properties as possible and, on the other hand, the number of parameters and material constants quantifying these properties is limited by actual possibility to evaluate these parameters, that is, material constants, and this either by measurements "in situ" or by specimen testing in laboratory. The rheological modelling of the rock mass is an extremely complex problem and, for that reason, some approximations have to be made during formulation of the mathematical model, regardless of its complexity. The level of approximation should, on the one hand, provide necessary accuracy of results regarding the stress-deformation behaviour of the rock mass and, on the other hand, it should enable a simple determination of material constants and parameters that are used in the mathematical model.

An experimental research of marl specimens, partly presented in this paper, was conducted under conditions of short time loading, and long term loading and unloading, in order to formulate a rheological model of soft rock behaviour under different stress conditions. This study also considered the need to evaluate adequate material parameters for the rock matrix, which was the main objective of this experimental research, and this through testing of marl which was selected as a representative rock from the group of most common soft rocks.

Material constants and other significant parameters of material behaviour were obtained based on creep tests on uniaxial specimens, and a rheological model was formulated for uniaxial stress in order to describe the stress-strain behaviour of material when subjected to short and long term loading. This paper presents results of a three-year laboratory testing of marl subjected to short and long term loading and unloading, with the purpose of defining a rheological model

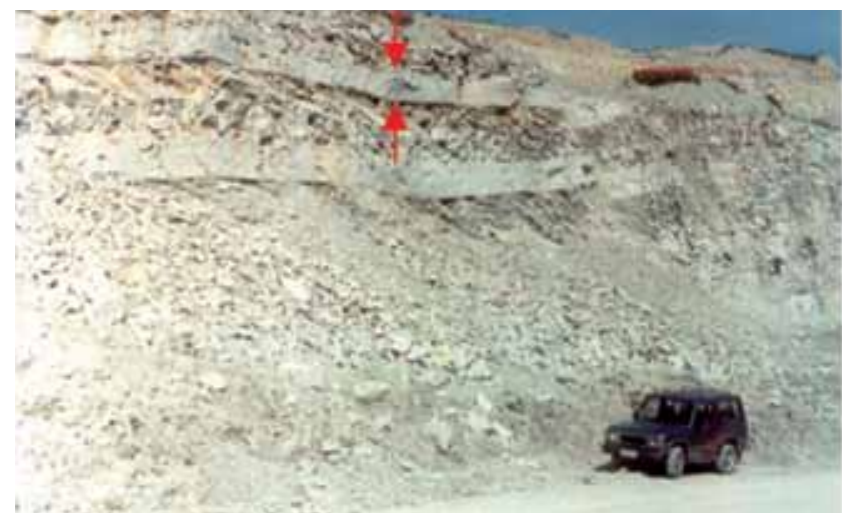

for soft rock that can be used as a basis for the stress-strain analysis by numerical methods.

\subsection{Sampling and specimen protection against moisture loss}

The coal overburden in the Potrlica Pit of the Coal Mine in Pljevlja (northern region of Montenegro) dominantly consists of thick marl layers, which mostly lie directly over the coal deposits. The thickness of the marl overlay varies from several tenths of meters to more than one hundred meters. The bench of the open-pit mine (Figure 1.a) came as a very suitable location for sampling the marl that has been selected for the purposes of this experimental research.

During rock block extraction, the objective was to obtain a block with a very even structure, i.e. the block free of macrocracks. Naturally, the lowest dissipation in the material structure has to be ensured where all laboratory specimens are cut out of a single compact rock block. The extraction of a rock block sufficient in terms of dimensions was carried out by blasting to enable the natural block disintegration process, thus mitigating the risk of hidden cracks in the block. The block presented in Figure 1.b, extracted from the layer shown in Figure 1.a, was found fully convenient based on its shape, size and other specified criteria. The block was relatively regular in shape, and its overall dimensions were $380 \times 90 \times 80 \mathrm{~cm}$. A blasting hole was bored into the block, with clear indication of the natural position of the block and, in particular, the vertical direction of its natural position. The block shown in the figure was extracted and transported to the stone cutting plant. The rotating cutter blade $280 \mathrm{~cm}$ in diameter was used to cut the block into plates measuring $10 \mathrm{~cm}$ and $15 \mathrm{~cm}$ in thickness. These plates were additionally processed using a rotating cutter blade $70 \mathrm{~cm}$ in diameter in order to obtain a prismatic shape, as presented in Figure 2.a.

In the creep test, the deformations resulting from the change in moisture content are regarded as an unwanted phenomenon. Therefore, in order to reduce changes in moisture content during the creep test, a thin layer of paraffin was applied on the specimen after placement of measurement bases (plates),

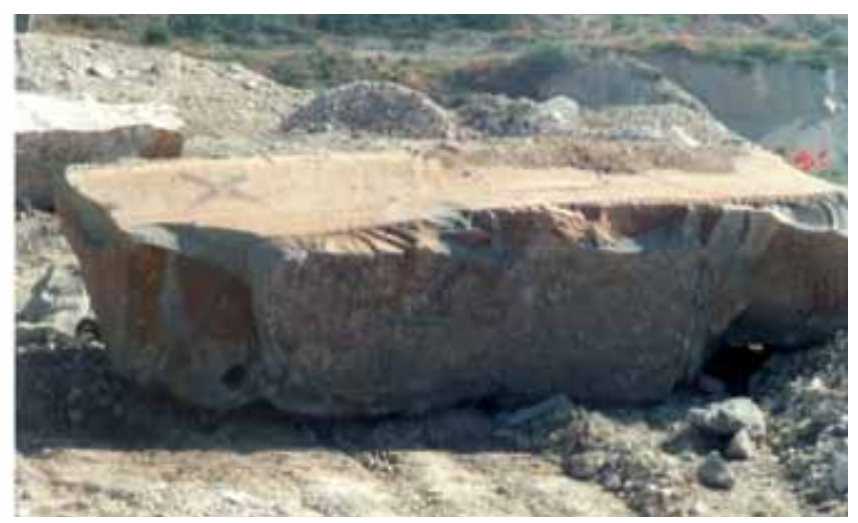

Figure 1. Open pit of the coal mine in Pljevlja (Montenegro): a) marl block extraction site; b) extracted grey marl block 

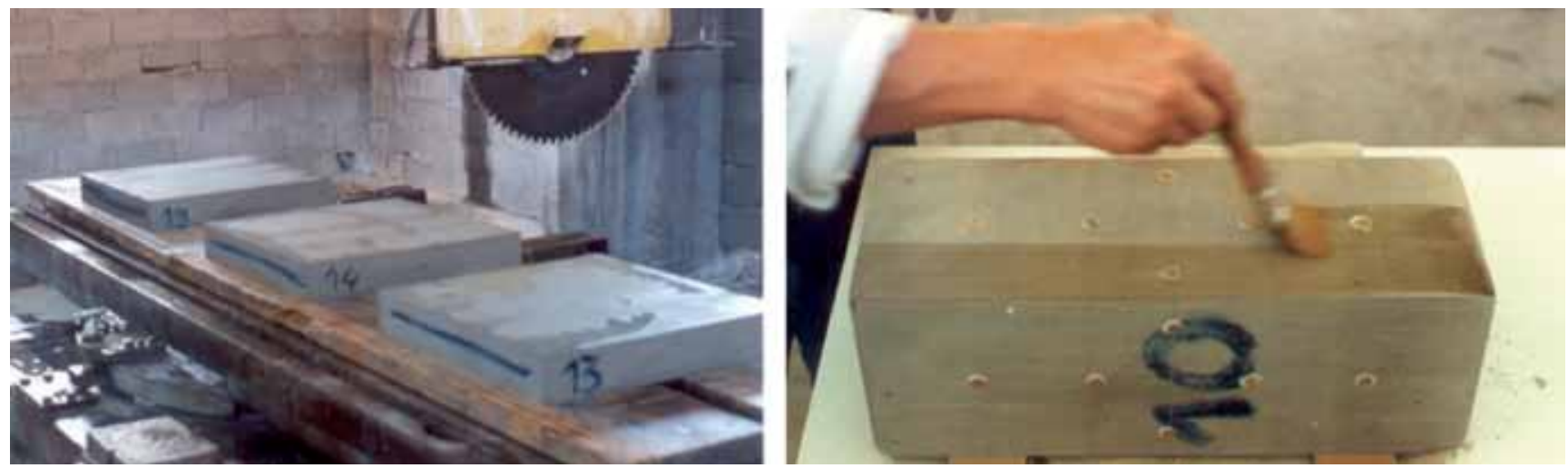

Figure 2. a) Plate cutting $(60 \times 60 \times 10 \mathrm{~cm})$ by a) rotating cutter blade $(\phi 70 \mathrm{~cm})$; b) Protection of specimens with paraffin

as shown in Figure 2.b. By applying this measure, the change in moisture content was significantly lowered and, even more importantly, the speed of the moisture content change was reduced and, consequently, the shrinkage of the rock material during the one-year research period was reduced to minimum. Paraffin-sealed specimens showed no macroscopic cracks, although this regularly occurs in case of specimens that are not protected by paraffin covering.

\subsection{Chemical and mineralogical content and material properties of tested marl}

The chemical study involved partial chemical analysis of marl specimens in order to determine the content of $\mathrm{CaO}, \mathrm{MgO}, \mathrm{CO}_{2^{\prime}}$ and insoluble residue. The $\mathrm{CaO}$ and $\mathrm{MgO}$ content in specimens was determined by a complex-metric method, the $\mathrm{CO}_{2}$ content by calcimetry, while the insoluble residue content in marl,i.e. the clay component, was determined quantitatively, by dissolving the carbonate component in the $0.01 \mathrm{M}$ acetic acid solution at the temperature of $50^{\circ} \mathrm{C}$. The insoluble residue, i.e. the clay component + quartz, was subjected to further mineralogical study. The microscopic image of the marl specimen immersed in nitro-benzol (microscope $450 x z 00 m$ ) at parallel nichols is

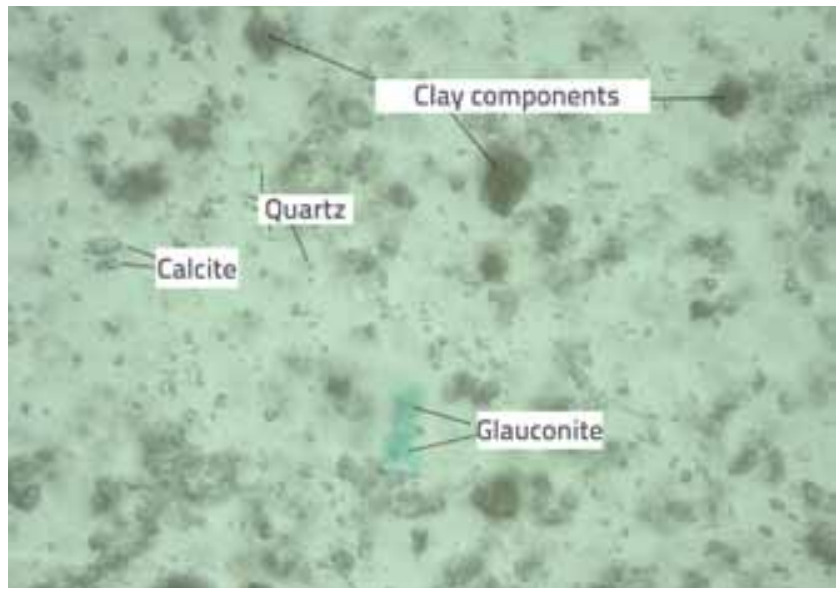

Figure 3. Microscopic image of the marl specimen immersed in nitrobenzol at parallel nichols ( 450 x zoom) shown in Figure 3, where the existence of mineral phases can be seen. The observed presence of glauconite in the specimen is rather interesting, as the glauconite may appear in marl, but it is not a frequently occurring mineral type.

According in its chemical content, the tested marl contains $\mathrm{CaCO}_{3}$ in the range from 48,10 to $48,30 \%$, while the content of insoluble residue (clay+quartzite) varies from 51,03 to $51,87 \%$. Regarding the mineralogical content, the calcite (46-48\%) and quartz $(12-13 \%)$ are dominant mineral phases, while in clay phase we find illite and smectite, montmorillonite, kaolinite, glauconite, transformed feldspar, and mica. The specimen moisture varies from 8 to 11 percent, while an average uniaxial strength of the material is about $\left(\sigma_{c}\right)=8,8 \mathrm{MPa}$. The volumetric weight of marl at its natural moisture content is approximately $18,8 \mathrm{kN} / \mathrm{m}^{3}$.

\section{Creep tests apparatus and testing procedures}

The experimental research on marl creep was carried out under conditions of limited change of room temperature, as changes of temperature for usual needs in tunnel-construction works are also limited. The creep deformation will therefore be treated as a value independent from temperature in further analysis.

\subsection{Uniaxial creep tests on marl}

In this experimental research, the uniaxial marl creep testing was conducted on two groups with three prismatic specimens, each measuring $15 \times 15 \times 40 \mathrm{~cm}$. A device with the "dead weight load" and a system of levers was used for loading and maintaining constant force over time, as shown in Figure 4. Each of six devices used in the testing was equipped with proving rings (constructed by the author of this paper) which enabled controlled variation of force acting on specimen during testing (less than $0.3 \%$ ). Each specimen was subjected to load for one hour. After loading or unloading, creep deformations were measured in the direction of vertical axis (longitudinal, direction 1-1) and horizontal axis (direction 2-2), on four unloaded sides of the specimen, as shown in Figure 5.a. 

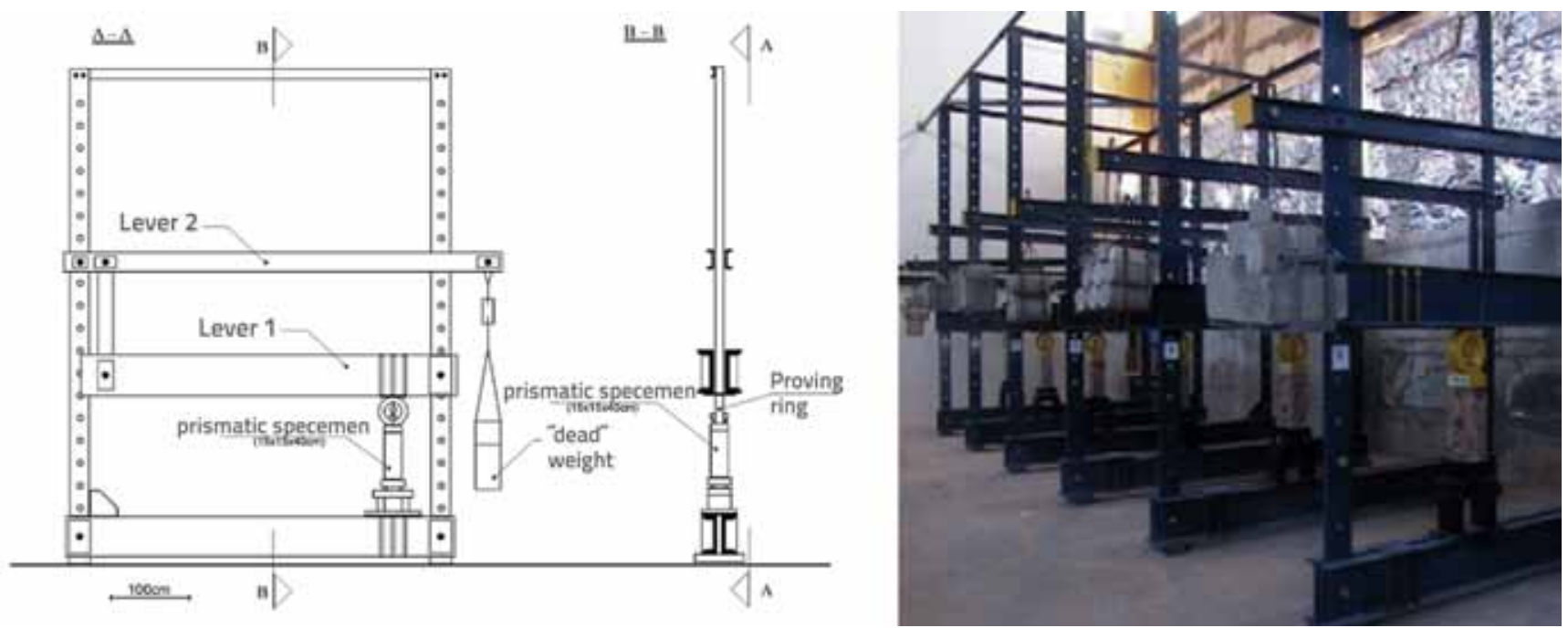

Figure 4. Device for uniaxial loading during the creep test
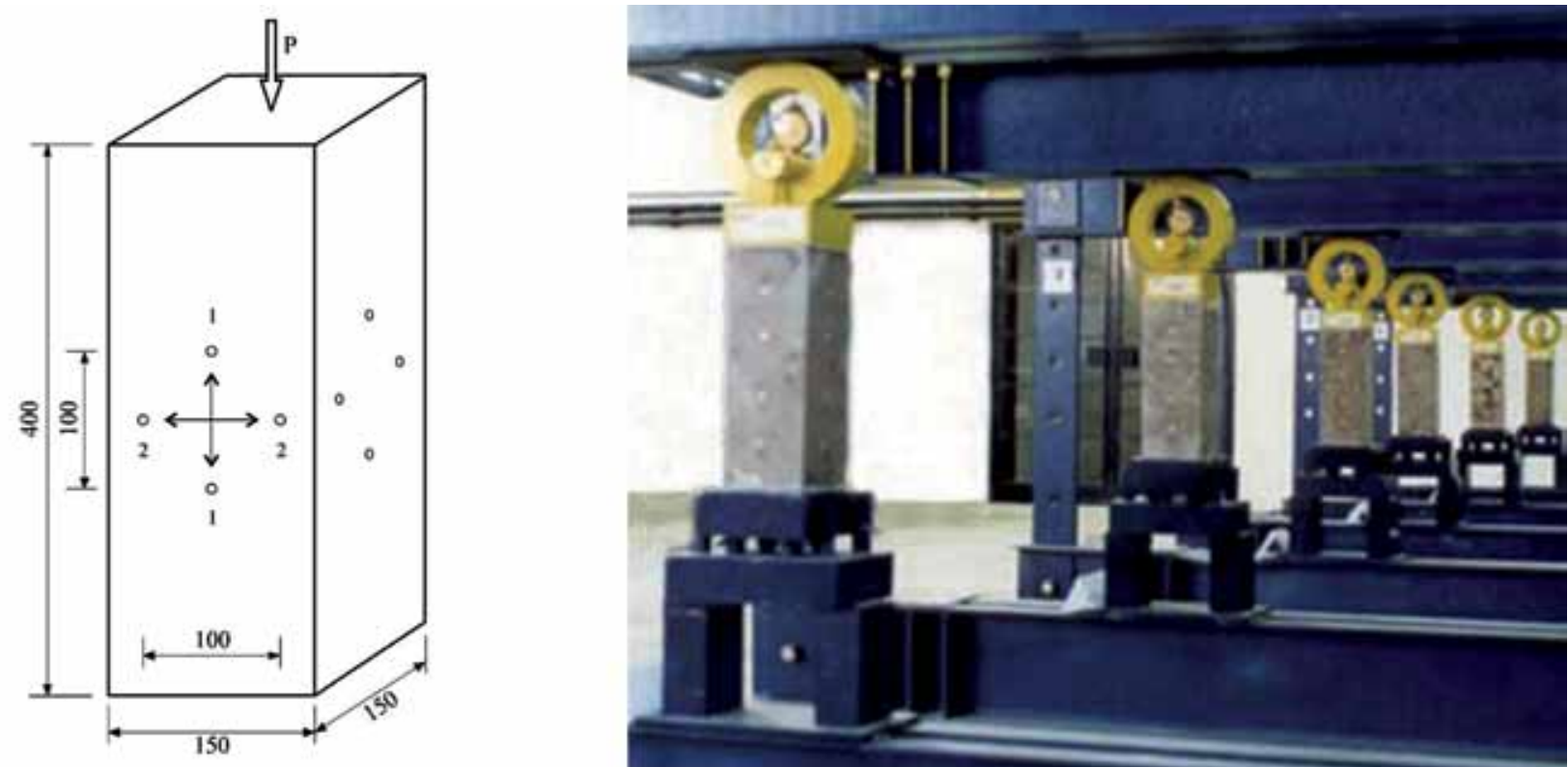

Figure 5. Prismatic specimen: a) layout of measurement points;b) specimens during the creep test (coated with paraffin)

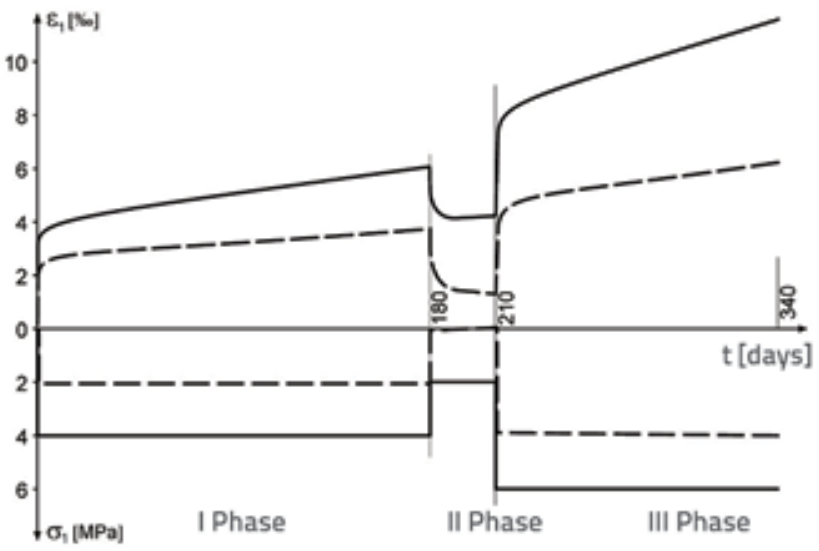

Figure 6. Diagram with creep test phases for uniaxially loaded prismatic specimens
The testing was performed in three phases: loading, unloading, and reloading to a higher level of stress, with maintenance of the constant value after stress change. The total duration of the test was 360 days (Phase I: 180 days, Phase II: 30 days, and Phase III: 150 days). The test procedure is presented in form of deformation-time and stress-time curves, cf. Figure 6 . In the creep test, the specimen loading was conducted in the increments of $25 \%$ of the defined level of stress, for every group of specimens. The loading of each specimen lasted one hour.

\subsection{Plate specimen testing}

The testing of plate specimens was conducted using devices shown in Figure 7.a. The vertical loading was imposed via the lever and dead load system, while horizontal force was 

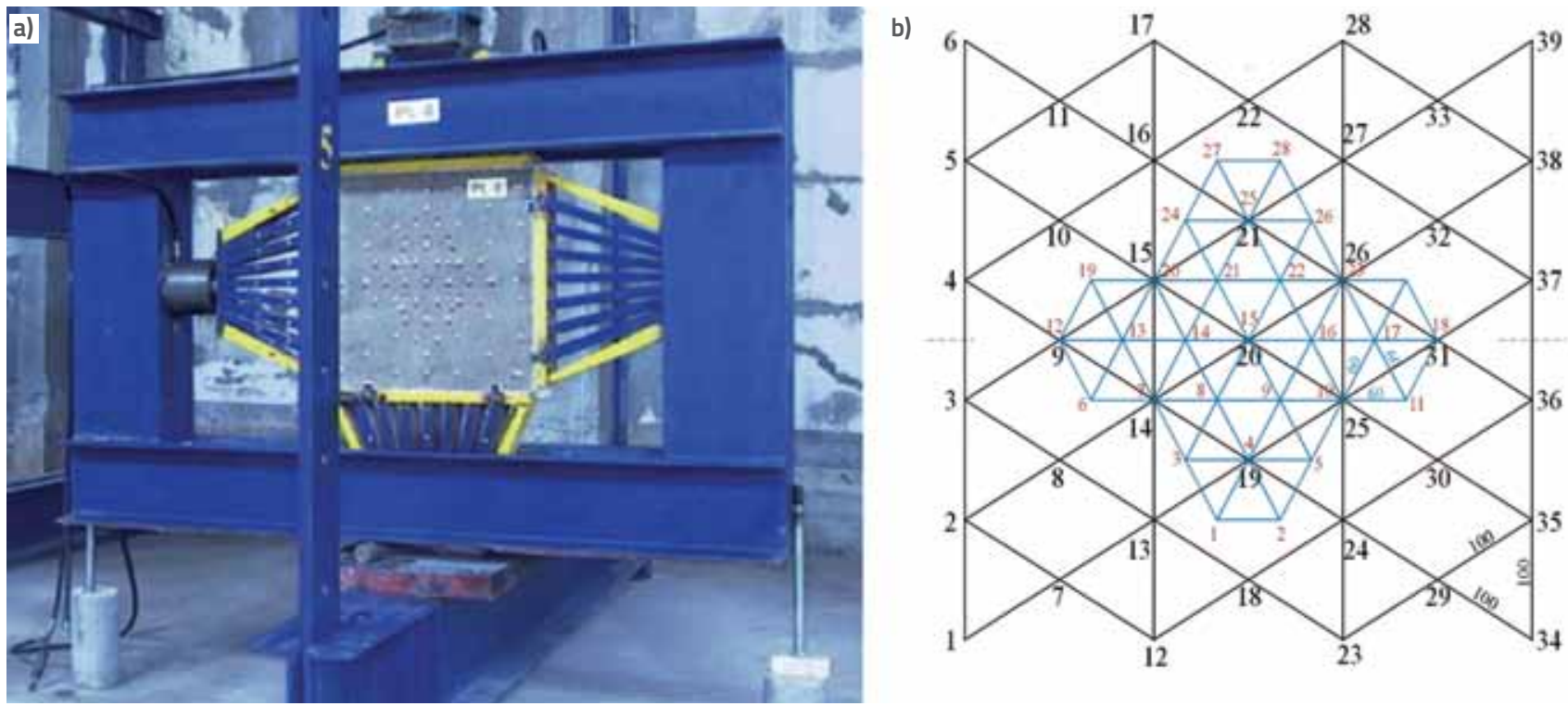

Figure 7. a) Bi-axial loading device - typical view; b) schematic view of plate specimen layout

applied by means of two inter-connected jacks. The vertical force was applied through the jack set between the load cell and the trapezoidal conveying element, while the horizontal force transfers to horizontal jack set between the secondary frame and the trapezoidal element according to the law of hydraulically connected tanks. Different ratios of vertical and horizontal pressure can be obtained by means of jacks with pistons of different cross-section. Using this device, the specimen can be "preserved" for months under the same vertical and horizontal pressures.

Plate specimens $(60 \times 60 \times 10 \mathrm{~cm})$ were loaded uniaxially and biaxially in their plane, in the $0.5 \mathrm{MPa}$ increments, in the period of an hour to the vertical stress of $2,0 \mathrm{MPa}$, which makes about $25 \%$ of the peak uniaxial strength of the examined marl. Three specimens were loaded uniaxially, and in the following three groups different ratios of horizontal to vertical pressure were obtained $\left(P_{h} / P_{v}=0,3 ; 0,5\right.$ and 1,0). The initiated stress state (with the constant ratio of $\mathrm{P}_{\mathrm{h}} / \mathrm{P}_{\mathrm{v}=}$ const.) was preserved during the ensuing 45 days, with measurement of deformation fields on both sides of the plate (Figure 7.b). This phase of the test was designed in such a way to determine the influence of lateral pressure on creep in vertical direction, and to establish variability of measured deformations (short and long) depending on the shape of specimens (prismatic or plate-shaped).

\subsection{Traditional triaxial compression testing}

The total of 24 specimens were prepared and tested in the three-axial device for measurement of pre-failure deformations. Each specimen was equipped with three rosettes or strain gauges set in the middle of the specimen a)

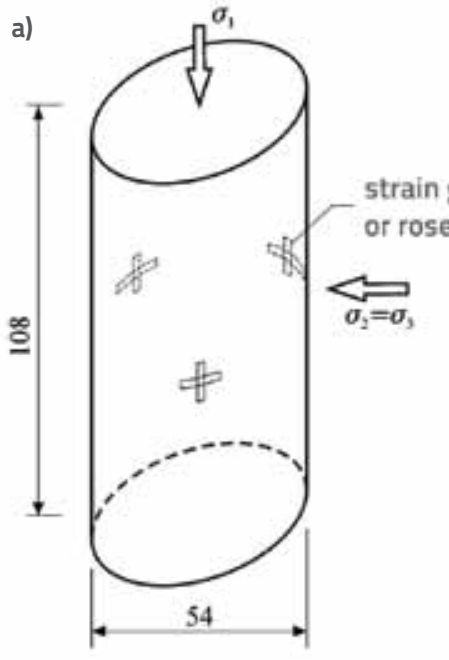

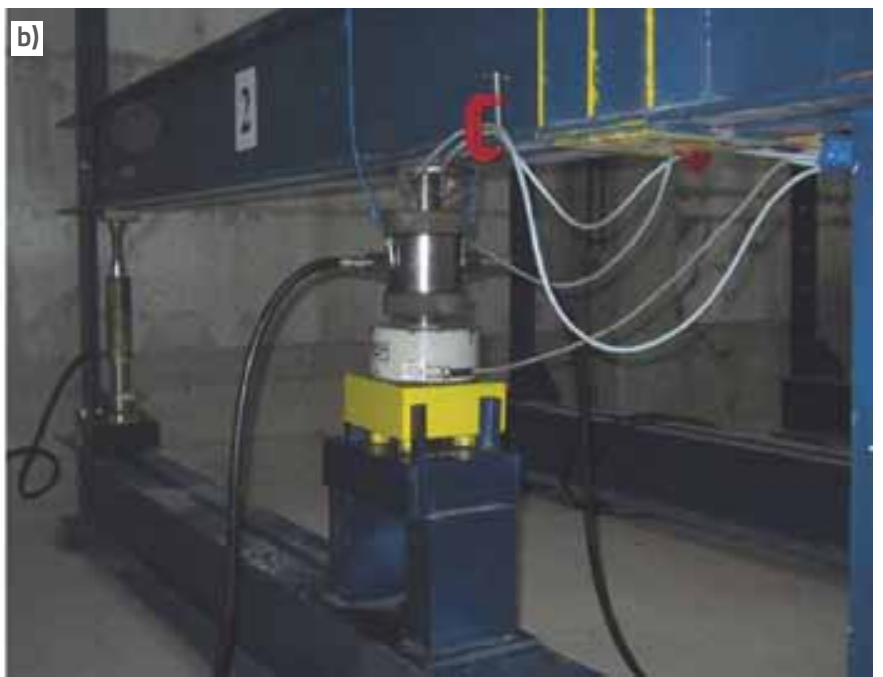

Figure 8. a) Cylindrical specimen for traditional three-axial testing; b) three-axial testing device - typical view 
height under the central angle of 1200 , as shown at the crosssection of the specimen (Figure 8.a).

Conventional triaxial compression tests enable us to analyse the influence of lateral stress on deformations. The lateral pressure $52=s 3$ (which varies in the set of tests) does not usually exceed the value of $50 \%$ of the peak strength obtained in uniaxial test with free lateral deformations. In general terms, this type of test can be conducted by applying the controlled loading force onto the specimen, or by controlling velocity of axial deformation. The creep test conducted on marl specimens in a shorter period of time (seven days) is a specific type of triaxial test with controlled loading force, where the level of stress remains constant throughout the testing.

The creep test was conducted in a traditional triaxial device on the total of 10 marl specimens using the constant vertical load of $2.0 \mathrm{MPa}$ in the period of 3 days, and the $4.0 \mathrm{MPa}$ vertical load in the following 3 days. Three specimens were tested without lateral pressure, the fourth one had lateral pressure of $1.0 \mathrm{MPa}$, and three specimens had the lateral pressure of $2.0 \mathrm{MPa}$. This short creep test offered some qualitative indicators about the examined rock behaviour over time when subjected to rotational symmetrical lateral pressure.

\section{Behaviour of soft rock under short-term loading and unloading}

Tests conducted under the short-term loading conditions are generally characterized by short duration of testing (several minutes to several hours, rarely longer) where test specimen deformations are predominantly due to changes in stress. Taking this into account, a general form of the relationship between the stress and deformation of rock can be written as follows: $\sigma=f(\varepsilon)$. For the application of numerical methods, the function $f(\varepsilon)$ should be a smooth, continuous and differentiable function, such as the tangent modulus which is the necessary requirement for certain numerical procedures. It is defined as a derivative of the function of stress per deformation, i.e.:

$E_{t}=\frac{d \sigma}{d \varepsilon}$

while for the arbitrary stress level, the secant modulus is defined as

$$
E_{s}=\frac{\sigma}{\varepsilon}
$$

\subsection{Models of stress-strain behaviour of rocks}

When approximating a real-life nonlinear stress-deformation behaviour by means of a linear relationship, for simpler stress dependent "problems" in rock mechanics, and with a low stress level, the level of error is quite insignificant, and so traditional constitutive relations from the linear theory of elasticity can be applied. For rock masses, where the stress- deformation relationship is highly non-linear at low stress levels, the traditional concept of linear elasticity based on Young's elasticity modulus should however be abandoned. The improvement of mathematical model of stress-deformation behavior in the direction of the real-time behavior of rocks is made by abandoning the assumption of linear elasticity, and by adopting the non-linear elastic model.

\subsection{Stress-dependent deformability modulus}

The dependence of the initial modulus of deformability on the lateral pressure becomes more important in the spatial state of stress (which usually characterizes stress dependent phenomena in rock mechanics) even in the domain of low stress, when we can speak about the stress-dependent elastic modulus [1]. The following expression is obtained by replacing the Young's modulus of elasticity $E$ with the stress-dependent modulus of elasticity $E\left(\sigma_{3}\right)$ in the stress-deformation dependence for the linear elastic material: $\sigma=E\left(\sigma_{3}\right) \varepsilon$ where $E\left(\sigma_{3}\right)$ can be the initial modulus of elasticity, tangent or secant modulus of deformability as defined by equations (1) and (2). In general terms, when the assumption of linear elasticity is abandoned, the non-linear relationship between the stress and deformation can be formulated as follows:

$\varepsilon^{n}=k^{n} P_{\left(\sigma_{3}\right)}\left(\frac{\sigma}{\hat{\sigma}}\right)^{m}$

where $n$ and $\mathrm{m}$ are material parameters, which are determined on the basis of experimental results using $\bar{\sigma}_{=1,0 \mathrm{MPa}}$ (normalization), $k$ is the coefficient of stress state, and $P\left(\sigma_{3}\right)$ is the function dependent on lateral pressure, as shown in Figure 9, $[2,3]$. When determining material parameters of nonlinear relationship between the stress and deformation of marl, the use was also made of available results of triaxial tests under different lateral stresses, which are presented in Figure 10. The regression analysis, with the application of the over squares method, produced necessary parameters for the definition of the function $P\left(\sigma_{3}\right)$ which can be expressed, for the examined marl, as follows:

$P\left(\sigma_{3}\right)=0,00022\left(\frac{\sigma_{3}}{\hat{\sigma}}\right)^{3.5}-0,03453\left(\frac{\sigma_{3}}{\hat{\sigma}}\right)+0,14727$

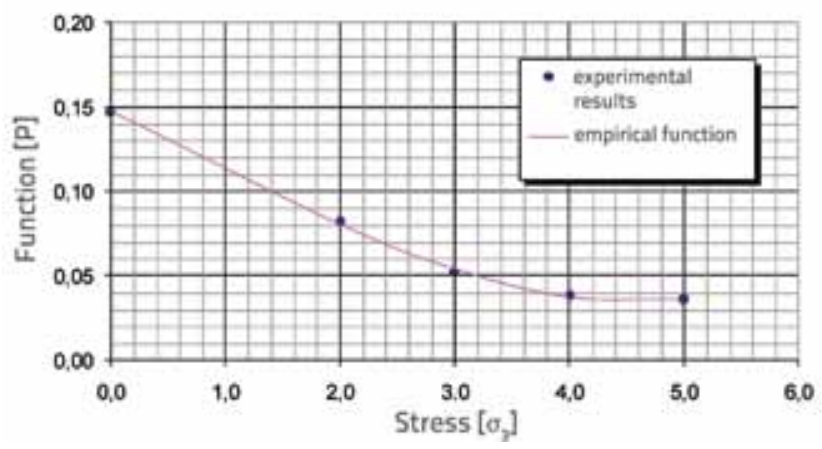

Figure 9. Function $\mathbf{P}\left(\sigma_{3}\right)$ - influence of lateral stress on axial 
By incorporating (4) into the equation (3) the stressdeformation dependence is obtained for the examined marl. For rotationally symmetric state of stress the ratio is $k=1,0$ ( $n$ $=2, m=3$ ), where strain is expressed in per thousand, while stress is expressed in MPa:

$\varepsilon_{1}=\left[P_{\left(\sigma_{3}\right)}\left(\frac{\sigma_{1}}{\hat{\sigma}}\right)^{3}\right]^{\frac{1}{2}}$

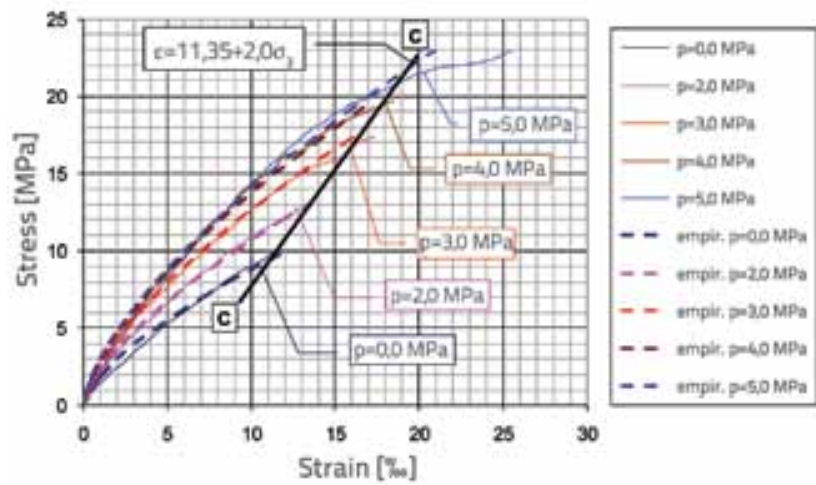

Figure 10. Comparative diagram of stress-strain dependence of marl according to empirical formula, and based on measured values ( $p$ - the lateral cell pressure)

The $\sigma-\varepsilon$ dependence curves, based on the given empirical formula (5) and measured values, are shown in Figure 10. The empirical curve approximates well real deformation values practically up to the level of failure stress where $\sigma_{3} \leq$ $4,0 \mathrm{MPa}$. When $\sigma_{3} \leq 4,0 \mathrm{MPa}$ (about $50 \%$ of uniaxial strength) the empirical formula applies to a limited stress level defined by the $\mathrm{C}-\mathrm{C}$ line. The empirical formula (5) developed for the description of stress-deformation relationships is a smooth, continuous and differentiable function, and it can be easily incorporated into numerical procedures. Lateral stress which is above the pressure of $4,0 \mathrm{MPa}$ for the examined marl, has no further effect on the increase of the modulus of deformability.

\section{Creep tests results for marl}

\subsection{Uniaxial creep test results for marl}

Results obtained by measuring creep deformation of prismatic specimens, at axial stresses from 2.0 MPa to 4.0 $\mathrm{MPa}$, are shown in Figure 11. The diagram clearly shows the zone of intensive creep of material in the axial direction during the first 20 days after the loading. The deformation increase in this period of time is non-linear in relation to the time. After this period, creep deformations increase linearly. It can also be noticed that the deformation gradient increase during the tested period of time is bigger for specimens subjected to higher stress. A comparative diagram of creep after unloading in axial direction is shown in Figure 12 for these two groups of prismatic specimens. This diagram clearly shows that a significant time dependent deformation "reverse creep" is also present during the process of unloading, in addition to the instantaneous elastic deformation (for details see: [4]).

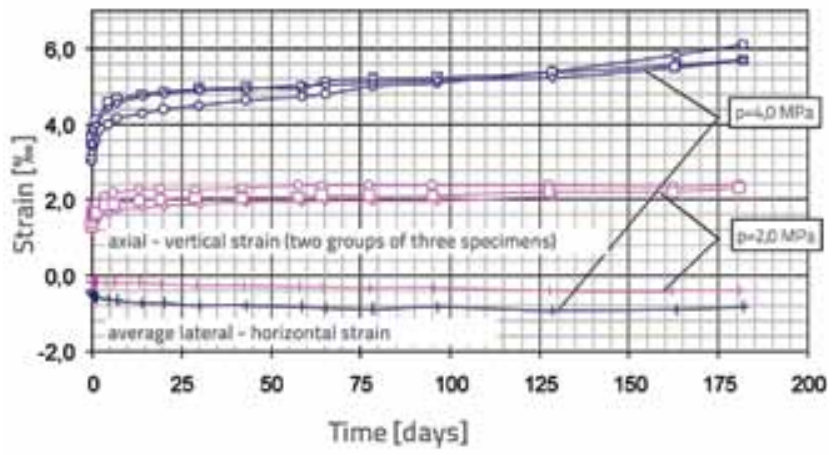

Figure 11. Comparative diagram of creep in axial and lateral direction under different stresses (two groups of three specimens)

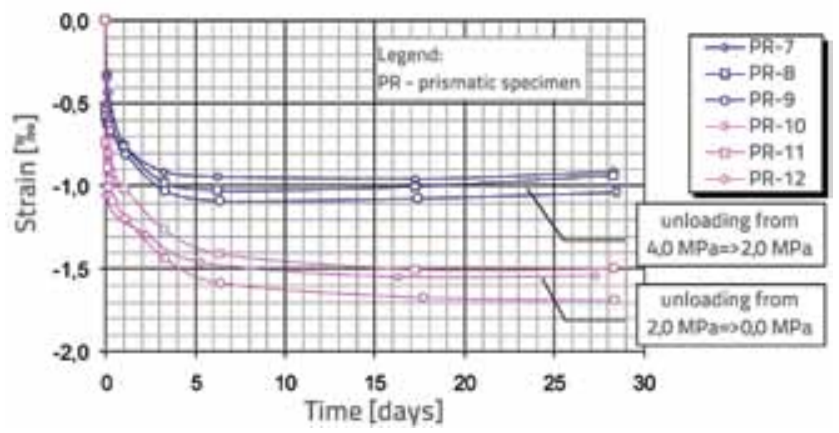

Figure 12. Comparative creep diagram after the total or partial unloading of prismatic specimens in the axial direction (two groups of three specimens)

\subsection{Creep test results for uniaxially and bi-axialy loaded plate specimens}

Under similar vertical stress, deformations measured on uniaxially loaded plate specimens are larger than deformations measured on prismatic specimens, cf. Figure 13. (red lines in Figure 13 denote measurement results on two different plate specimens; blue line denotes an average creep deformation for prismatic specimens subjected to the same level of stress.) The diagram given in Figure 13. shows that an increase in creep deformation significantly reduces in horizontal direction after 10-15 days. This phenomenon can be explained by different behaviour of materials in vertical and horizontal directions, i.e. by the presence of anisotropy of material (Eh/Ev=2, E-elasticity modulus), which is the consequence of a particular micro-structure of marl that forms during its sedimentation. Evidently, the creep of specimens loaded vertically in horizontal direction is predominantly occurring immediately after the loading, that is, in the zone of the primary creep component - delayed elasticity. When full elastic deformations are developed, including delayed deformations, the increase in creep deformation is drastically reduced. 
In case of bi-axially loaded plate specimens, the horizontal deformation showed fluctuations in the first 5 to 7 days after the loading. In the ensuing period, the creep in horizontal direction could be registered only for specimens subjected to the same vertical and horizontal force. For all other specimens with ratios $k=\sigma_{h} / \sigma_{v}=0,5$, horizontal deformations in time retained the value of initial deformation, and in the ratio of $k=$ $\sigma_{h} / \sigma_{v}=0,3$ horizontal deformations were almost the same as those of prismatic specimens. In the ratios $k=\sigma_{h} / \sigma_{v} 1.0$ and 0.5 the horizontal deformation is the shrinkage deformation, and in the ratios $k=\sigma_{h} / \sigma_{v}=0.3$ the horizontal deformation is the extension deformation [5, 6]. (for creep test results for bi-axially loaded plate specimens see [5].)

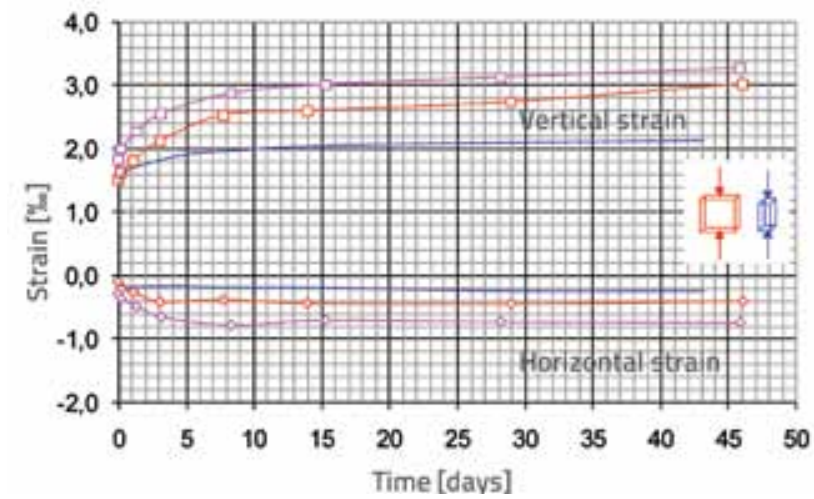

Figure 13. Creep diagram for uniaxially loaded plate specimens (stress: 2.0 MPa)

\subsection{Results of creep test in in conventional three- axial device}

The diagram presented in Figure 14 simultaneously shows creep test results (strain - time) for uniaxially loaded cylindrical specimens $(\mathrm{d} / \mathrm{h}=5.4 \times 10.8 \mathrm{~cm})$, and average creep values for prismatic specimens $(15 \times 15 \times 40 \mathrm{~cm})$ subjected to uniaxial stress amounting to 2.0 and 4.0 MPa. Test results indicate that there is no significant difference in time dependent deformations between prismatic and cylindrical specimens. The diagram in Figure 15 shows creep test results for three-axially loaded

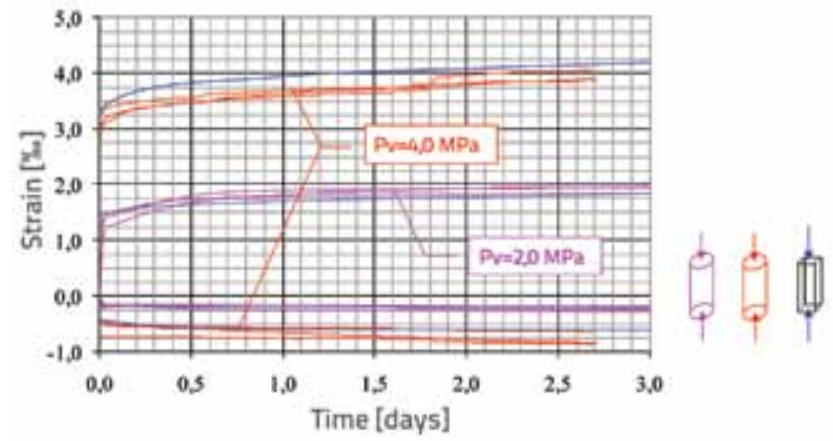

Figure 14. Comparative uniaxial creep test results for prismatic and cylindrical specimens subjected to uniaxial stress of $\mathbf{2 . 0}$ and 4.0 MPa cylindrical specimens with different lateral pressure. Full lines indicate axial (vertical) strain, while dash lines indicate tangential (horizontal) strain. The level of radial deformation after one day of loading is preserved for all specimens, and this regardless of the intensity of radial stress in the considered domain, while axial deformation points to the influence of lateral stress on time-dependent deformations.

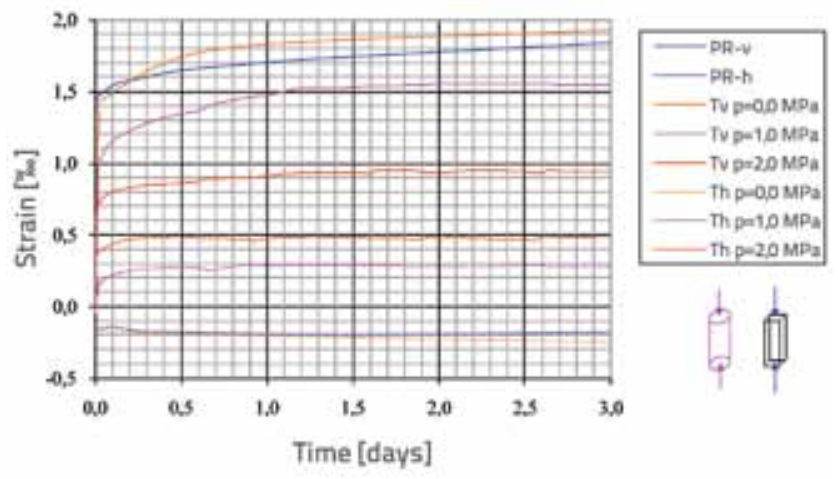

Figure 15. Three-axial creep test results for cylindrical specimens and uniaxial test results for prismatic specimens subjected to axial stress of $2.0 \mathrm{MPa}$. (Legend: PRprismatic specimen; Tv/Th- vertical/horizontal strain for cylindrical specimen; $\mathrm{p}$ - lateral cell pressure.)

\section{Reological model}

\subsection{Behaviour of rock under constant long-term load}

The diagram of typical deformation behaviour of rock under long-term constant load is presented in Figure 16. If load $S$, causing a stress state $\sigma$ which is lower than the stress state defined by the "short-term" yield condition, is applied to the rock, then adequate current deformation $\varepsilon^{e l}$, is induced as the first "response" of the material to the stress change, as shown in diagram given in Figure 16. As the time passes, deformations that develop without any change of the

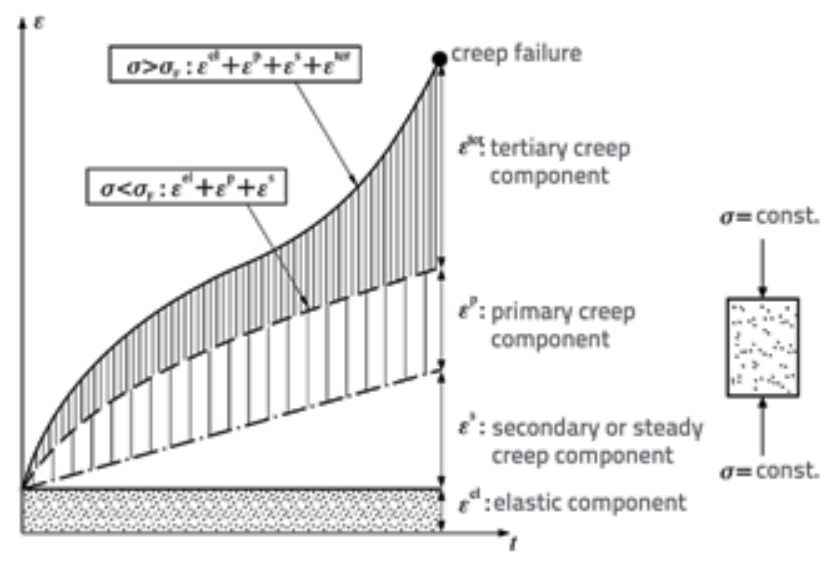

Figure 16. Elastic component and time-dependent component: primary, secondary and tertiary creep in uniaxial test 
established stress state are time dependent deformations, i.e. deformations dependent on creep, [8,9].

When the stress state is below the yield condition $(\sigma<\sigma$ Figure 16), time dependent deformations - rock creep, as well as the creep of many other materials, are characterized by primary and secondary creep components. When the stress level reaches the yield stress zone $\left(\sigma<\sigma_{F}\right.$, Figure 16), the creep strain reaches the tertiary component, in addition to the primary and secondary ones, which eventually leads to failure of the material (for additional generally known characteristics of deformation behaviour of rocks, the reader is directed to some already classical sources including: [7, 8, 9], etc.).

\subsection{The rock creep in the domain of stress under the yield limit}

Usual constitutive relationships which refer to time dependent deformations are mostly based on the assumption of linear elastic behaviour of the material for $\mathrm{t}=\mathrm{t}_{\mathrm{o}}$ (during the stress loading) and creep of material for $t>t_{0}$. The total deformation is the sum of elastic deformation $\varepsilon^{e l}$ (for $t_{=} t_{0}$ ) and creep deformation $\varepsilon^{t}$ (for $\left.t>t_{0}\right)$ :

$\varepsilon=\varepsilon^{e l}+\varepsilon^{t}$

When the stress level is under the yield limit $\left(\sigma<\sigma_{p}\right.$ Figure 16.), the creep deformation is limited to primary and secondary creep, and the total strain is the total of elastic strain, and the strain of primary and secondary creep:

$\varepsilon=\varepsilon^{e l}+\varepsilon^{p}+\varepsilon^{s}$

Constitutive equations which describe time dependent effects, which are going to be the subject-matter of further analysis, do not include effects of volumetric change or breakage of rock mass. Thus, this analysis is related to rock and rock mass phenomena in rock mechanics to which the continuity assumption can be applied. When analyzing the problem of rock mass creep, which includes discontinuities, constitutive connections established in this paper can be used for analyzing deformation of the rock monolith, while special relationships between displacements and forces have to be formulated for the behaviour of discontinuities.

When creating general constitutive equations in the triaxial field of stress, which includes time dependent deformations, a certain number of initial assumptions derived from the analysis of the experimental results is also introduced. Thus for general constitutive equations in the field of three-dimensional stresses, the following assumptions are introduced into the model (they are in principle also included in the Wallner's model, 1983): only homogenous and isotropic rocks are taken into consideration, small displacements and rotations of material are also assumed, constitutive equations are applicable in a certain stress domain which is restricted to short-term surface of failure, which in turn is incorporated in constitutive equations, and there is no volumetric change during primary and secondary creep [10].

\subsection{Constitutive Wallner's model}

Because of its general approach in the inclusion of rock characteristics, and its formulation in three-axial stress state, this paper refers to the constitutive Wallner's law (developed on a number of rock salt tests) as an appropriate basis for description of the stress-deformation behaviour of different rock types and other geo-materials, [10, 11, 12, 13]. In further analysis, the suitability and adequacy of this model for description of time dependent deformations of marl, after loading and unloading, is analyzed, as well as the role of marl as the representative rock chosen from the group of soft rocks.

The mechanical model of the constitutive Wallner's law for one-dimensional state of stress and deformation is presented in Figure 21. The mechanical model consists of five different rheological bodies, and each of them describes an appropriate deformation component. All deformation components are irreversible except for elastic components. The volumetric deformation appears in elastic domain in tertiary creep and during the state of tensile failure. This rule is valid when there are volumetric changes during the primary and secondary creep.

\subsubsection{Elastic deformation component}

The relationship between the stress and deformation in the domain of elasticity is formulated, in a general form, by the following differential equation:

$\left\{\frac{\partial \varepsilon^{e l}}{\partial t}\right\}=[C]\left\{\frac{\partial \sigma}{\partial t}\right\}$

where:

$\varepsilon \quad$ - is the vector of component deformations

$\sigma \quad$ - is the vector of component stress

[C] - is the matrix of coefficient of flexibility

When the stress-deformation relationship is independent from time, the equation (8) is reduced to the equation:

$\{\varepsilon\}=[D]^{-1}\{\sigma\}=[C]\{\sigma\}$

In case of general three-axial stress and deformation state, the equations from the generalized Hook law are applied.

\subsubsection{Primary creep}

The general form of connection of the stress and deformation of primary creep is described, in the three-dimensional case, according to the Wallner model by the following differential equation: 


$$
\left\{\frac{\partial \varepsilon^{p}}{\partial t}\right\}=\frac{1}{\eta_{p}}\langle G\rangle\left\{\frac{\partial \sigma_{\text {eff }}}{\partial\{\sigma\}}\right\}
$$

where:

$$
\begin{aligned}
& \langle G\rangle=E_{p}\left[\left(\frac{\sigma_{\text {eff }}}{E_{p}}\right)^{m}-\varepsilon_{\text {eff }}^{p}\right],\langle G\rangle=\left\{\frac{0}{G} \frac{z a}{z a} \frac{G<0}{G \geq 0}\right. \\
& \sigma_{\text {eff }}=\sqrt{\frac{3}{2}\left(S_{x}^{2}+S_{y}^{2}+S_{z}^{2}+2 \sigma_{x y}^{2}+2 \sigma_{y x}^{2}+2 \sigma_{z x}^{2}\right)} \\
& \varepsilon^{p}{ }_{\text {eff }}=\sqrt{\frac{2}{3}\left(\varepsilon_{x}^{2}+\varepsilon_{y}^{2}+\varepsilon_{z}^{2}+\frac{1}{2} \varepsilon_{x y}^{2}+\frac{1}{2} \varepsilon_{y x}^{2}+\frac{1}{2} \varepsilon_{z x}^{2}\right)}
\end{aligned}
$$

$E_{p}$ - is the strain-hardening modulus

$\eta_{p}$ - is the viscosity (for primary creep)

$m$ - is the stress exponent (for primary creep).

The primary creep is described by three characteristic material parameters $E_{p} \eta_{p} \mathrm{i} m$. Components of the deviatoric part of the stress tensor are $S_{x^{\prime}} S_{y^{\prime}} S_{z^{\prime}} \sigma_{x y^{\prime}} \sigma_{y z^{\prime}} \sigma_{z x}$ while components of the deviatoric part of the deformation tensor are $\varepsilon_{x^{\prime}}, \varepsilon_{y^{\prime}} \varepsilon_{z^{\prime}}$ $\varepsilon_{x y^{\prime}} \varepsilon_{y z^{\prime}} \varepsilon_{z x^{\prime}}$ One invariant of the deviatoric part of the stress tensor was adopted for the plastic potential $\sigma_{\text {eff }}\left(\sigma_{e f f}=\frac{3}{\sqrt{2}} \tau_{\text {okt }}\right.$, where $\tau_{o k t}$ - is the octahedral shearing stress), and it describes the deviation from the hydrostatical stress state $\left(\sigma_{1}=\sigma_{2}=\sigma_{3}\right)$, while $\varepsilon_{\text {eff }}^{p}$ is an appropriate invariant of the deviatoric part of strain tensor. The plastic potential $\sigma_{\text {eff }}$ and $\varepsilon^{p}$ eff are defined by components of the deviatoric part of stress tensor, i.e. by components of the deviatoric part of strain tensor.

\subsubsection{Secondary creep}

The general form of the relationship between the stress and deformation for secondary creep is described by a differential equation:

$\left\{\frac{\partial \varepsilon^{s}}{\partial t}\right\}=\frac{1}{\eta_{s}} H\left\{\frac{\partial \sigma_{\text {eff }}}{\partial\{\sigma\}}\right\}$

where:

$H=P_{o}\left(\frac{\sigma_{\text {eff }}}{P_{o}}\right)^{n}$

$\eta_{s}=\frac{P_{o}}{a} ; P_{o}=1.0 \mathrm{MPa}$

where:

$a$ - is the creep parameter

$n$ - is the normalized stress exponent (for secondary creep)

The secondary creep is described by two parameter constants of the materials $a$ and $n$.

Components of rheological model, which appear after the yield conditions are attained, are not the subject matter of this research, which is why they are not presented in greater detail (for more details, the reader is directed to $[3,9,10]$.

\subsection{Defining material parameters of the primary and secondary component of creep}

Creep tests carried out on marl at stresses below the yield point indicate that time dependent deformations represent a significant component of total deformations. Thus, in the uniaxial creep test conducted under rather low stresses (about $25 \%$ of the peak uniaxial compression strength), the time dependent deformations after 6 months attain the level of deformations induced by the initial stress change. For that reason, a constitutive model, which describes the stressdeformation behaviour of this type of rock as consistently as possible, is required to model the time dependent deformation component.

The primary and secondary creep values are described by five characteristic material parameters. To define these parameters, deformation measurements must be conducted on specimens subjected to constant load for an extended period of time. Compared to material parameters, obtained from force and deformation measurements, and used to describe elastic behaviour of materials, the material parameters, which describe the creep of material, cannot be obtained in the same way; they shall be determined by regression analysis based on the strain - time creep curve. In addition, the creep test must be conducted under different stress states in order to define the influence of stress states on creep deformations.

In order to define material parameters of creep, while also taking into account different stress states that are induced by some test types, the differential equations (10) and (11), which describe primary and secondary creep for a general three-dimensional stress state, must be reduced to specific cases that are appropriate for the stress state under which the creep tests are conducted.

If we take that laboratory creep tests were carried out under the uniaxial state of stress, the transfer to the creep equation for this specific stress case, from general equations according to the model of Wallner, is of highest significance for the following analysis. Once the uniaxial stress state is included, and after an appropriate processing of equations (10) and (11), the equation describing creep under uniaxial stress state is obtained:

$\varepsilon=\frac{1}{E} \sigma_{1}+\frac{3}{2}\left(\frac{\sigma_{1}}{E_{p}}\right)^{m}\left(1-e^{-\frac{2}{3} \frac{E_{p}}{\eta_{p}} t}\right)+a\left(\sigma_{1}\right)^{n} t$

where the first item describes the elastic behaviour, the second one the primary creep, while the third item describes the secondary creep. The equation (12) can be used to determine material parameters $E_{p}, m, \eta_{\rho}, a$ and $n$ from the creep diagram which is obtained from deformation measurements under uniaxial creep test conditions. The results of uniaxial laboratory tests conducted on prismatic specimens - creep tests after loading and after the complete or total unloading - were used to determine unknown 


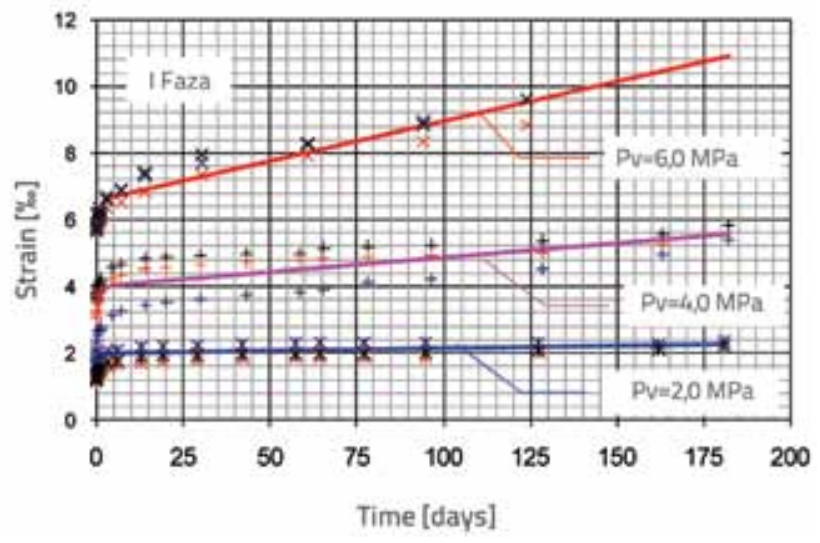

Figure 17. Theoretical function of marl creep for different uniaxial stress levels $(=2,0 \mathrm{MPa}, 4,0 \mathrm{MPa}$ and $6,0 \mathrm{MPa})$

material parameters of the examined marl (Figure 17). The determination of material parameters on the basis of the least difference of the theoretic creep function and the measured values, was performed using the regression analysis and the over squares method as a tool for determining optimum values of required parameters based on available measurement data.

\subsubsection{Creep after loading}

The results of creep tests for uniaxially loaded specimens subjected to the stress of 2.0,4.0, and 6,0MPa, were used for 180 days ("dotty" value on the diagram in Figure 17) in order to determine optimum material parameters of the theoretic function (12). Three specimens were tested at each load level. When determining optimum empirical functions by defining primary and secondary creep parameters, it is also necessary to define initial deformations as induced by stress change. A linearly elastic model was adopted to define these deformations. In this case, the value of secant modulus of deformability (cf. Equation 2), obtained during uniaxial testing for certain stress levels, was used. Characteristic values of this modulus, which are used to define optimum parameters of the function (12) for marl, are presented in Table 1.

Table 1. Values of secant modulus of marl deformability for defining primary and secondary creep parameters

\begin{tabular}{|l|c|c|c|}
\hline Characteristic stress [MPa] & 2,0 & 4,0 & 6,0 \\
\hline $\begin{array}{l}\text { Secant modulus of marl deformability } \\
\text { [GPa] }\end{array}$ & 1,45 & 1,38 & 1,06 \\
\hline
\end{tabular}

The comparative diagram of measured deformations ("dotty" values), and deformation according to the equation (12) for defined pressure stress (full lines) during the creep test, is shown on Figure 17. Values of optimal material parameters defined by regression analysis, with strains expressed in 1/1000, are shown in Table 2 . The values obtained for five required marl parameters define the primary and secondary creep after loading.

Table 2. Values of material parameters of marl for the primary and secondary creep after loading

\begin{tabular}{|c|c|c|c|c|}
\hline \multicolumn{3}{|c|}{ Primary creep } & \multicolumn{2}{c|}{ Secondary creep } \\
\hline $\begin{array}{c}E_{p} \\
{[\mathrm{MPa}]}\end{array}$ & $\begin{array}{c}\eta_{p} \\
{[\mathrm{MPa} \cdot \mathrm{d}]}\end{array}$ & $m$ & $\begin{array}{c}a \\
{[1 / \mathrm{d}]}\end{array}$ & $n$ \\
\hline 225 & 425 & 0,06 & $2,71 * 10^{-4}$ & 2,5 \\
\hline
\end{tabular}

\subsubsection{Creep after stress reduction (decrease of load)}

It can be seen from the marl creep diagram after stress reduction (Figure 12) that, after the total unloading, the creep deformation inclines towards a horizontal asymptote. After about thirty days, a reversible creep deformation is fully developed (tending towards the horizontal asymptote) and it achieves, according to its intensity, the value of a reversible elastic deformation. After partial stress reduction, from 4,0 to $2,0 \mathrm{MPa}$, the reversible creep deformation (in the same direction) occurs in the first seven days, and then the material starts to creep in the opposite direction under the actual stress of 2,0MPa (shrinkage under the remaining pressure).

The Wallner's model shows proper approximations of marl creep after stress increase (i.e. under load) only if optimum parameters are defined by regression analysis on the basis of total deformation measurements (stress induced + time induced), as shown in Section 5.3. However, the material behaviour after stress reduction cannot be described consistently by means of the Wallner's constitutive model. In fact, according to the Wallner's model, all deformation components, besides elastic ones, are irreversible and that is why any time dependent reversible deformation cannot appear after stress reduction. This is in contradiction with the experimental evidence exposed in Figure 12, which points to a significant reversible creep deformation in marl rock.

Assumptions on reversibility of time dependant deformations of the Wallner's model, developed on the basis of rock salt tests, cannot be applied on marl. On the one hand, there are significant time deformations after unloading and thus the assumption that they are equal to zero is not correct and, on the other hand, attempts to describe time deformations after stress reduction by this model (same function of primary creep with just a change in mathematical sign) did not give acceptable results compared to experiments on marl rock. In the light of the above considerations, and in order to enable proper mathematical description of marl behaviour after stress reduction, relevant corrections had to be made in order to introduce some changes in the available constitutive model. By analysing the marl creep results obtained by uniaxial testing after stress release, we came to conclusion that the primary creep (or better to say delayed elasticity) does not depend on actual stress level as it was formulated in the constitutive 
Wallner's model, but rather on the stress difference by which creep is induced (loading or unloading). Namely, if the initial rock creep (marked as $\varepsilon^{p}$ ) is taken to be a delayed elasticity, then the "direction" of this component of time deformation is in accordance with the "direction" of elastic deformation. If the load which causes pressure increases, the deformation of delayed elasticity is the shrinking deformation (diagram in Figure 18.a). In case of the total or partial unloading (stress reduction), the deformation of delayed elasticity has a direction of reversible elastic deformation (in extension), as shown in the diagram given in Figure 18.b.

In cases when the stress difference is an increase from zero to a certain pressure stress, the Wallner's model remains completely unchanged because the stress difference (stress increase) is equal to the applied stress and, besides the formal record (replacement of the stress with the stress difference), there are no corrections in that part of the constitutive model. After correction the equation (12) can be formulated as follows:

$\varepsilon=\frac{1}{E} \sigma_{1}+\frac{3}{2}\left(\frac{\Delta \sigma_{1}}{E_{p}}\right)^{m}\left(1-e^{-\frac{2}{3} \frac{E_{p}}{\eta_{p}} t}\right)+a\left(\sigma_{1}\right)^{n} t$

At the stress release, the assumption, acceptable until now, that the elastic deformation is the only reversible deformation, and that this is the reason why the reversible primary creep exists, is to be abandoned. The primary creep in the newly suggested model depends on the stress change difference (and not on the current stress state as it is formulated in the Wallner's model) and, after stress reduction, it has the opposite sign compared to the primary creep after stress increase, as shown in the diagram given in Figure 18.b. The secondary creep depends on the actual stress pressure, and it always has a positive sign for the stress pressure (shrinkage), as shown in diagrams presented in Figure 18.b.

For the constitutive model defined in such a way, optimum

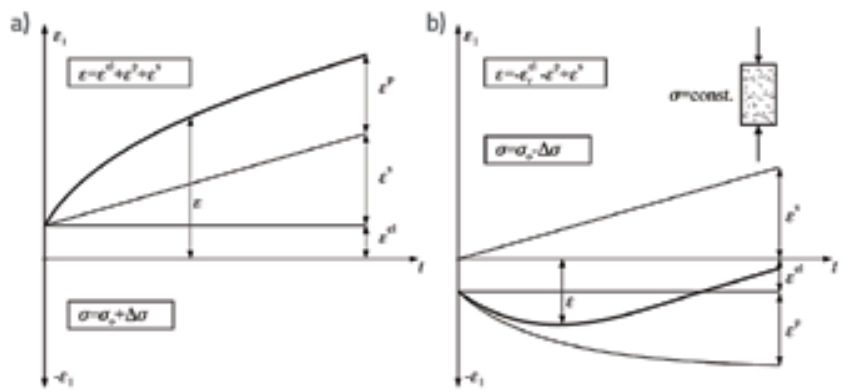

Figure 18. Components of creep deformation after: a) stress increase; b) stress reduction

material parameters for the equation (13) are also defined by regression analysis, and also based on time-dependant deformation measurements after stress reduction, in the second phase of testing involving prismatic specimens. Namely, during the stress history path, a certain strengthening - consolidation of natural rock material appears during creep at a higher stress level. Consequently, parameter values describing primary and secondary creep components $\left(\hat{E}_{p}, \hat{\mu}_{p}, \hat{m}\right.$ i $\left.\hat{a}, \hat{n}\right)$ must both be used. Limited experimental records suggest that the stress level and duration of the event of loading in prehistory affect the change of these parameters.

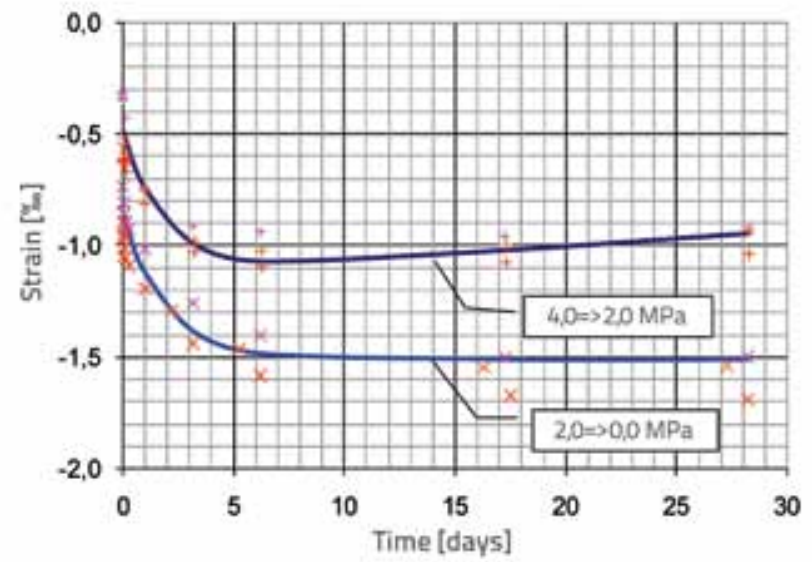

Figure 19. Theoretical creep function after stress reduction (from 4.0 to $2.0 \mathrm{MPa}$, and from 2.0 MPa to $0.0 \mathrm{MPa}$ )

Curves of marl creep according to the newly suggested constitutive model after stress reduction (full line) are shown in the diagram given in Figure 19. Measured time deformations after stress reduction are marked by "dots" in the same diagram. The values of required parameters obtained by the regression analysis for marl, which define the primary and secondary creep after stress reduction, are shown in Table 3. In narrow terms, these parameters are valid only after the same prehistory regarding both stress state and creep duration. When the stress is reduced, the reversible modulus of elasticity $E_{r}$ is to be used; and it differs from the initial modulus of elasticity, i.e. the modulus that is applied at loading. An approximate value of the reversible modulus is larger than the value of the initial elasticity modulus, and hence reversible deformations are lower than the initial ones for the same stress change [3].

Table 3. Parameters of primary and secondary creep after stress reduction

\begin{tabular}{|c|c|c|c|c|}
\hline \multicolumn{2}{|c|}{ Primary creep component } & \multicolumn{2}{c|}{$\begin{array}{c}\text { Secondary creep } \\
\text { component }\end{array}$} \\
\hline $\begin{array}{c}E_{p} \\
{[\mathrm{MPa}]}\end{array}$ & $\begin{array}{c}\eta_{p} \\
{[\mathrm{MPa} \cdot \mathrm{d}]}\end{array}$ & $m$ & $\begin{array}{c}a \\
{[1 / \mathrm{d}]}\end{array}$ & $n$ \\
\hline 225 & 150 & 0,008 & $1,48^{*} 10^{-4}$ & 2,5 \\
\hline
\end{tabular}




\subsection{Mathematical formulation of the elastic rock deformation - basis for numerical models}

The following two components have to be defined for time dependent deformations induced by the stress state maintained under the yield surface: deformation of delayed elasticity (primary creep) and deformation of secondary creep. Experimental results of the marl creep tests conducted in the scope of this research indicate that the first component of time deformations - delayed elasticity - depends on previous stress difference, while the other component depends on the actual stress state.

The diagram of uniaxial creep according to the M. Wallner's model and, alternatively, based on the model presented by the author of this paper, is shown in Figure 20. It can easily be noticed that the Wallner's model neglects reversible time deformations after unloading (Figure 20). The mechanical model of rock behaviour according to the author of this paper is shown in Figure 21 (M. Wallner's model is also given for comparison purposes). The model consists of five different rheological bodies, and each of them describes an appropriate deformation component [3].

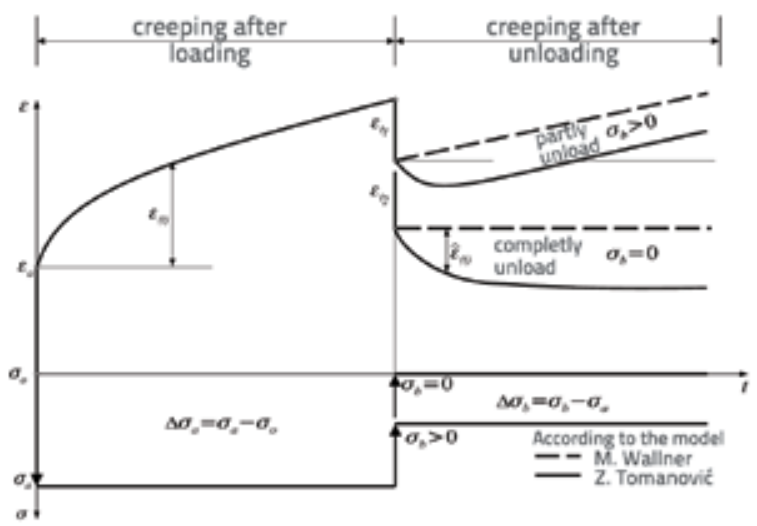

Figure 20. Time dependent deformations after loading and unloading according to the $\mathrm{M}$. Wallner model and the model presented by the author of this paper

One invariant of the deviatoric part of stress tensor is adopted for the plastic potential $\sigma_{\text {eff }}$ It describes deviation from the hydrostatical stress state $\left(\sigma_{1}=\sigma_{2}=\sigma_{3}\right)$. The change of plastic potential during stress change from $\sigma_{i}$ to $\sigma_{j}$ is marked with $\Delta \sigma_{e f f}$ i.e. with $\Delta \sigma=\sigma_{j}=\sigma_{i}$. An appropriate invariant of the deviation part of tensor of deformation is $\varepsilon^{p}{ }_{\text {eff }}$ (harmonized with equations presented in Section 5.3). The total deformation with stresses that are subject to the condition of plasticity is obtained as the total of component deformations:

$\varepsilon=\varepsilon_{e}+\varepsilon_{p}+\varepsilon_{s}$

where:

$\varepsilon_{e}$ - is the elastic strain (induced by the stress change)

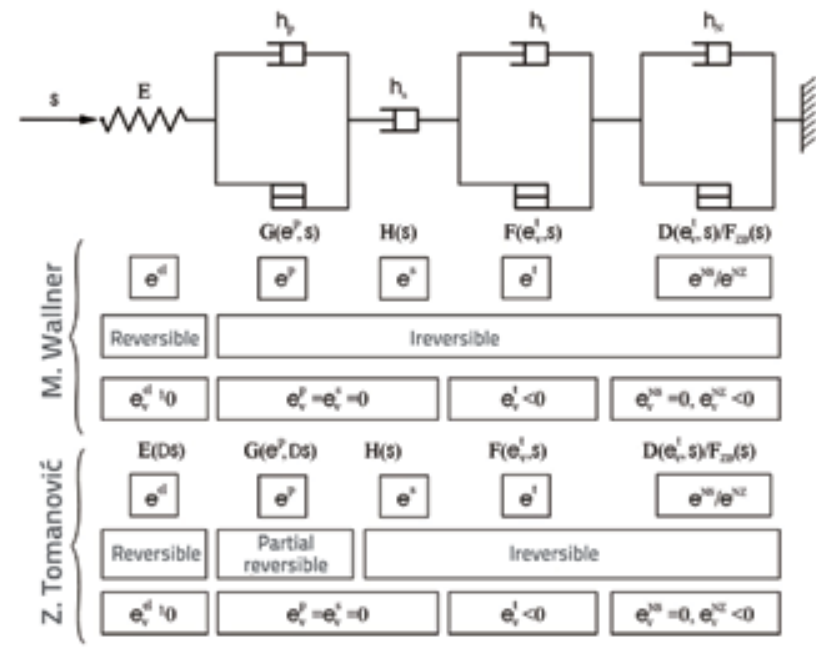

Figure 21. Mechanical model of constitutive equations of the stressdeformational behaviour of rock according to M. Wallner and the author of this paper

$\varepsilon_{p}$ - is the primary creep strain (delayed elasticity)

$\varepsilon_{s}$ - is the secondary creep strain

The mathematical description of rock behaviour by a rheological model of the rock mass is necessary for practical application of the constitutive model presented in the paper. The mathematical formulation of a rheological model, when the stresses are under the yield limit, is presented as a summary in Table 4 for a three-dimensional case. Due to the fact that deformations are time dependent, the equations are given as time derivatives [3].

Mathematical formulation allows incorporation of complex rheological models into numerical programs for the purpose of solving stress-dependent phenomena in rock mechanics. The most interesting application of the newly developed rheological model lies in the analysis of the stress-strain state around tunnel openings. A secondary stress state develops around the tunnel opening, after the excavation. This secondary stress is characterized by the decrease of stress in radial directions or in the direction normal to the contour of the opening, and by the increase of stress in the direction tangential to the contour of the opening. The biggest stress changes occur at the contour of the excavation where the radial stress drops to zero, while the tangent stress is usually at its maximum. Even in homogeneous and isotropic materials, this change in stress causes a change in the deformation modulus of rock, which is a function of the actual lateral pressure.

The rheological model presented in this paper includes the influence of lateral pressure on the axial deformation, i.e. on the modulus of deformability. An additional feature included in the model is the creep strain of rock mass after stress reduction, which fully depends on the changes in stress fields that occur in the rock mass after cavity excavation. 
Table 4. Review of constitutive equations for rock at the stress under plasticity conditions

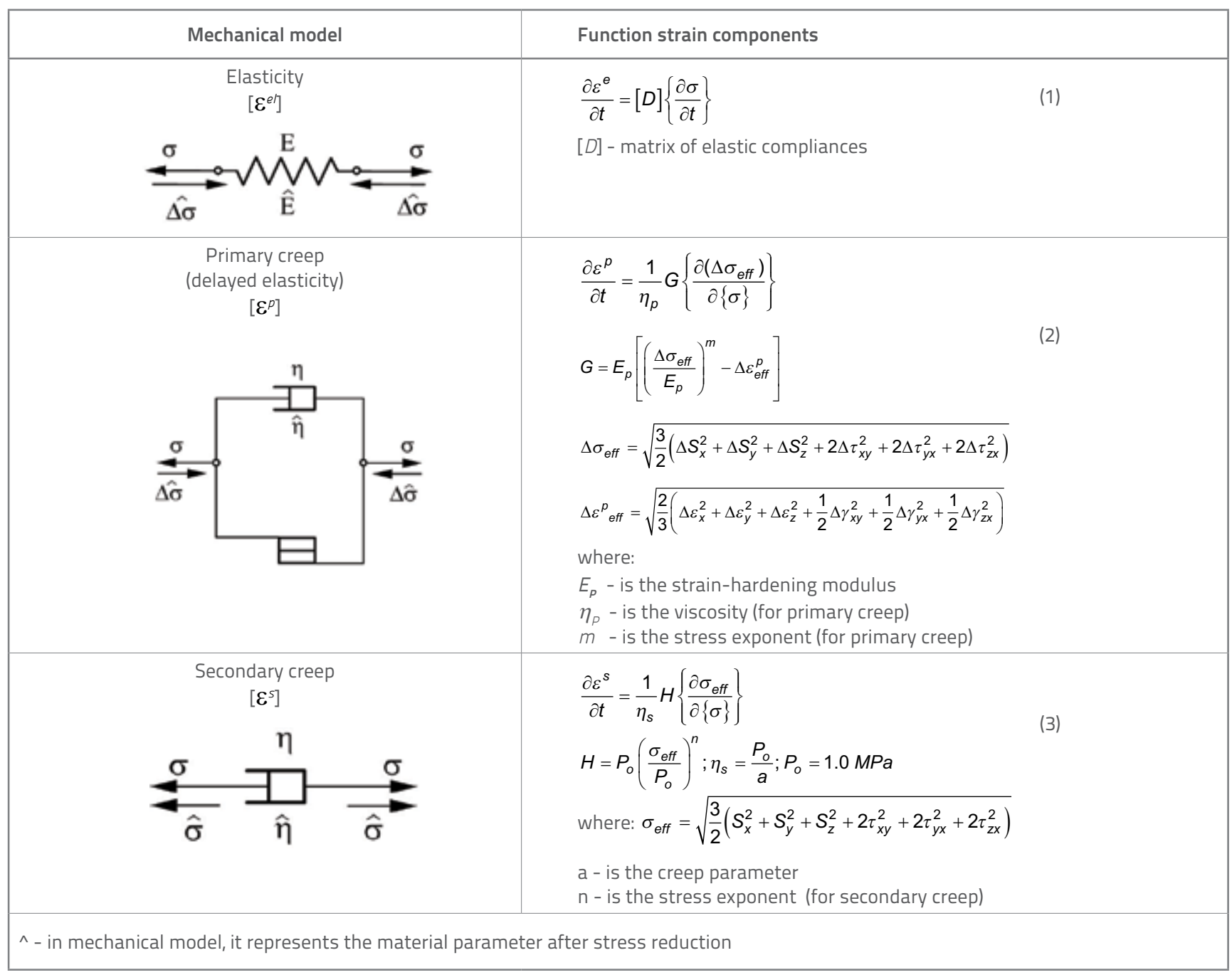

Thanks to the incorporation of the stress-dependent modulus of elasticity, and the time-dependent deformation, in appropriate components (numerical procedures) of the software, the analysis of stresses around the opening in the rock mass can provide solutions that are significantly closer to the real stress-strain state in the rock around the tunnel opening. It is important to emphasize that material parameters included in the rheological model can be obtained through relatively simple laboratory experiments, and so the numerical procedure for the determination of stresses and strains appears quite appropriate.

\section{Conclusion}

Creep tests conducted on uniaxially loaded prismatic specimens indicate that the marl with the constant uniaxial pressure exhibits significant time dependant deformations, namely the creep. Thus creep deformations which develop within 6 months almost reached the level of the values of the short term deformation induced by initial change of stress. During the first 20 days after loading, the increase in deformation was non-linear in relation to time. This is the zone of intensive creep of material in axial direction, or the primary creep. After this period, in the zone of secondary creep, the creep deformations become smaller and the increase in deformation is almost linear. Additionally, the gradient of deformation increases over time, and it is larger in case of specimens subjected to a higher stress.

Stress-strain diagrams for marl, obtained through conventional triaxial testing at different levels of lateral pressure, indicate that errors are smaller, which is due to approximation of nonlinear stress-strain relationship with linear relationship, and errors resulting from the fact that the effect of triaxial stress on deformation was neglected. By incorporating stress-dependent moduli of elasticity (using software based on the conventional elasticity theory) in the analysis of stress around the opening in the rock mass, solutions that are significantly closer to the real stress-strain state in situ are obtained, especially if they are 
compared with solutions from the classical theory of elasticity, which usually overestimate the level of tangent stresses close to opening contours.

The research presented in the paper shows that current rheological rock models for creep can not, in their original form, correctly describe reversible time deformations after unloading, and this because their starting assumption is that the component of primary creep depends on the actual stress state, and at full unloading this component becomes zero. By analyzing the results of marl creep tests after unloading, it was established that the primary creep (delayed elasticity) actually depends on the stress relaxation difference which precedes the reversible creep, rather than on the stress state of material after relaxation, as suggested by the presently used rheological models.

\section{REFERENCES}

[1] Ewy R.T., Cook N.G.W.: "Deformation and Fracture Around Cylindrical Openings in Rock - I", Int. J. rock Mech. Min. Sci.,Vol. 27. No 5. pp. 387-407, 1990.

[2] Tomanovic, Z.: Stress dependent modulus of deformability of marl under short term loading (In Serbian). Geotehnički aspekt građevinarstva, Savez građevinskih inženjera i tehničara Srbije i Crne Gore, Kopaonik, pp. 101-106, 2005.

[3] Tomanovic Z.: "Stress-strain behavior of marl under short term loading" (in serbian) Građevinska nauka i praksa, Univerzitet Crne Gore, Građevinsi fakultet, Žabljak, p.p. 815-820, 2006

[4] Tomanovic, Z.: Rheological model of soft rock based on test on marl. Int. J. Mechanics of Time-Dependent Materials, Springer, pp. 135-154, 2006.

[5] Tomanovic, Z.: Influence of Ko on creep properties of marl. Int. J. Acta Geotechnica Slovenica, pp. 14-29, 2009.

[6] Taqo Xu, Chun-An Tang, Jian Zhao: Modeling of Rheological Deformation of Inhomogeneous Rock And Associated TimeDependent Responce of Tunnels., Int. Jour. Of Geomechanics, march/april, 14-159, 2012.

[7] Bergues, J., Nguyen D. and Hoetit, N.: Time dependent behaviour of hard marls. The Geotechnics of hard Soils-Soft Rock, Evangelista \& Picarelli, Balkema, Rotterdam, 1998.
These experimentally confirmed phenomena have been included in a corrected rheological model, as suggested by the author of this paper, and thus the deformation induced by the stress difference (elastic component) and the primary creep component, depends on the stress change which precedes the creep of the material, while all other components depend on the actual state of stress. The suggested rheological model allows correct description of time-dependent deformations after loading and also after the total or partial unloading, which is especially significant for stress-deformation conditions in the rock mass around tunnel openings and around other types of underground cavities. It should be emphasized that it is necessary to determine previously cited material parameters for description of creep after loading, because of development of pre-consolidation of the material in the process of creep after loading.

[8] Pande G.N., Beer G. \& Williams J.R.: Numerical method in rock mechanics. Jon Wiley \& Sons Ltd., 1990.

[9] Jaeger J.C. \& Cook N.G.W., and Zimmerman: Fundamentals of rock Mechanics, Blackwell Publishing, 2007.

[10] Cristescu, N.D. and Hunsche, U.: Time effects in Rock Mechanics. John Willey \&Sons., 1998.

[11] Wallner, M.: Stability calculation concerning a room and pillar desing in rock salt. International Congress for Geotechnics, Melbourne, 1983.

[12] Doring, T., Kiehl, J.R.: Das primare, sekundare und tertiare Kriechen von Steinsalz - Ein dredimensionales rheonomes Stoffesetz. Geotechnick vol. 3, 194-199, 1993.

[13] Keihl, J.R., Reim, J.: A three-dimensional constitutive law for rock salt including transient, steady state and accelerated creep, failuer as well as post failuer behaviour. Proc. 9th ISRM Congres, Vol. 2, Paris, 917-920, 1999.

[14] Bergues J. \& Nguyen D., Hoetit N.: Time dependent behaviour of hard marls, The Geotechnics of hard Soils-Soft Rock, Evangelista \& Picarelli, Balkema, Rotterdam, 1998.

[15] Goodman R.: Introduction to Rock Mechanics, John Willey \&Sons., 1989. 